\title{
BMR
}

\section{Association of interleukin gene polymorphisms with the risk of coronary artery disease}

\author{
H.T. Yang, S.L. Wang, L.J. Yan, P. Qian and H.Y. Duan \\ Department of Cardiology, Henan Provincial People's Hospital, Zhengzhou, China \\ Corresponding author: H.T. Yang \\ E-mail: haitao_yang3@163.com \\ Genet. Mol. Res. 14 (4): 12489-12496 (2015) \\ Received April 9, 2015 \\ Accepted August 2, 2015 \\ Published October 16, 2015 \\ DOI http://dx.doi.org/10.4238/2015.October.16.16
}

\begin{abstract}
We conducted a case-control study to investigate the genetic variants Interleukin-1 $\beta(I L-1 \beta)+3953 \mathrm{C} / \mathrm{T}$ (rs1143634), IL-6 -174G/C (rs1800795), IL-8 -251T/A (rs4073), and IL-10 -1082A/G (rs1800896) and $-819 \mathrm{C} / \mathrm{T}$ ( rs 1800871) in the development of coronary artery disease (CAD). A total of 410 individuals with CAD were enrolled between January 2012 and December 2014. Genotyping of the five gene polymorphisms was performed using the polymerase chain reaction combined with restriction fragment length polymorphism methodology. By multivariate logistic regression analysis, we found that the frequencies of the $\mathrm{CC}$ genotype and the $C$ allele of $I L-6-174 \mathrm{G} / \mathrm{C}$ were significantly correlated with a higher risk of CAD; the adjusted ORs $(95 \% \mathrm{Cls})$ were 2.37 (1.37-4.14) and 1.49 (1.19-1.86), respectively. In addition, the $A G$ and $G G$ genotypes and the $G$ allele of $I L-10$-1082A/G were also significantly associated with a higher risk of CAD, and the ORs $(95 \% \mathrm{Cls})$ were $1.42(1.04-1.95), 2.16$ (1.423.30), and 1.56 (1.27-1.93), respectively. However, $I L-1 \beta+3953 \mathrm{C} / \mathrm{T}, I L-8$ $-251 \mathrm{~T} / \mathrm{A}$, and $/ L-10-819 \mathrm{C} / \mathrm{T}$ did not significantly correlate with CAD risk.
\end{abstract}


Our study suggests that the IL-6 -174G/C (rs1800795) and IL-10 -1082A/G (rs1800896) polymorphisms might be involved in the pathogenesis of CAD, and likely contribute to the genetic susceptibility for CAD.

Key words: Interleukin gene; Polymorphism; Coronary artery disease

\section{INTRODUCTION}

Cardiovascular disease is a complex-trait disease and is the leading cause of morbidity and mortality worldwide, including in China (Go et al., 2014; He et al., 2005). Coronary artery disease (CAD) is the most common heart disease associated with atherosclerosis, the development of which involves a complex, multistep, and multifactorial process, including both genetic and environmental factors (Guo et al., 2010; Go et al., 2014). It has been reported that hypertension, hypercholesterolemia, diabetes, obesity, and tobacco smoking as well as alcohol drinking play critical roles in the development of CAD (Marenberg et al., 1994). However, environmental factors are not the best predictors of CAD risk, suggesting that genetic variants might influence the development of CAD. Previous studies have reported that a number of genetic polymorphisms might play an important role in the development of CAD including cytochrome P450 17A1 (CYP17A1), toll-like receptors, metallothionein $2 \mathrm{~A}$, and retinol binding protein 4 , as well as matrix metalloproteinase 1 (Qintao et al., 2014; Wan et al., 2014; Yang et al., 2014; Dai et al., 2015; Guven et al., 2015).

It has been reported that inflammatory processes influence the progression of atherogenesis, and that cytokines are involved in the migration of neutrophils, lymphocytes, and antigen-presenting cells including dendritic cells and cells of a monocyte/macrophage lineage (Kaur et al., 2013). Polymorphisms in cytokine genes could alter the function of protein expression and thus influence their roles in the process of cardiovascular disease. Specifically, previous studies have indicated that genetic variants of interleukin genes, such as interleukin-1 $(I L-1 \beta), I L-1 \alpha$, $I L-6, I L-10, I L-16, I L-18$, and IL-23A could affect the development of CAD (Romani et al., 2014; Armingohar et al., 2015; Chi et al., 2015; Jia et al., 2015; Tripathi et al., 2015; Yue et al., 2015).

Identification of such genetic variants could help evaluate the risk of CAD; for example, by identifying high-risk individuals. In this study, we conducted a case-control study to investigate the role of the genetic variants $I L-1 \beta+3953 C / T$ (rs1143634), IL-6 -174G/C (rs1800795), IL-8 -251T/A (rs4073), and IL-10-1082A/G (rs1800896) and -819C/T (rs1800871) in the development of CAD.

\section{MATERIAL AND METHODS}

\section{Subjects}

In the present case-control study, a total of 410 individuals with CAD and 410 unaffected individuals were enrolled from Henan Provincial People's Hospital between January 2012 and December 2014. The patients with CAD were diagnosed by angiography, and CAD was defined as the presence of at least one significant coronary artery stenosis of $\geq 50 \%$ luminal diameter, as identified by coronary angiography. The patient exclusion criteria were myocardial spasms or a myocardial bridge, congenital heart disease, childhood hypertension, severe kidney or liver disease, or malignant tumors. A total of 410 subjects were randomly selected from the physical examination center in our hospital. The control subjects were diagnosed as having no history of atherosclerotic lesions or CAD. 
Clinical and demographic details of all included patients and controls were recorded from a self-designed questionnaire or medical records. A written informed consent was obtained from each subject before entering the study group. The collection of blood samples for this study was previously approved by the Ethics Committee of Henan Provincial People's Hospital.

\section{Genetic analysis}

All patients and control subjects were asked to provide a $5 \mathrm{~mL}$ peripheral venous blood sample after enrolling into this study. The collected blood samples were stored at $-20^{\circ} \mathrm{C}$ until use. Genomic DNA was extracted from peripheral blood using the TIANamp Blood DNA kit (Tiangen Biotech Co., Ltd., Beijing, China). Genotyping of IL-1 $\beta+3953 \mathrm{C} / \mathrm{T}$ (rs1143634), IL-6 -174G/C (rs1800795), IL-8 -251T/A (rs4073), and IL-10 -1082A/G (rs1800896) and -819C/T (rs1800871) polymorphisms was performed using polymerase chain reaction combined with restriction fragment length polymorphism (PCR-RFLP) analysis. The primers and probes for the five gene polymorphisms were shown as follows. For $I L-1 \beta+3953 \mathrm{C} / \mathrm{T}$ (rs1143634), the primers were $5^{\prime}-$ CTC AGG TGT CCT CGAAGAAAT CAAA - 3' and 5' - GCT TTT TTG CTG TGA GTC CCG - 3', and the restriction enzyme used for RFLP was Taql. For IL-6 -174G/C (rs1800795), the primers were 5' - TTA CTC TTT GTC AAG ACA TGCC A - 3' and 5' - ATG AGC CTC AGA CAT CTC CAG - 3', and the restriction enzyme was SfaNI. For IL-8 -251T/A (rs4073), the primers were 5' - CAT GAA GCA TCT GTA ATT AAC TG - 3' and 5' - CTC ATT TTT CAT TAT GTC AGA G - 3', and the restriction enzyme was Munl. For -1082A/G (rs1800896), the primers were 5' - CCA AGA TTA CAC TAC TAA GGC TTC TTG AGG A - 3' and 5' - AGG TAG TGC TCA CTA TTA CC - 3', and the restriction enzyme was BseRI. For IL-10 -819C/T (rs1800871), the primers were 5' - ATC CAA GAC AAC ACT ACT AA - 3' and 5' - TAA ATA TCC TCA AAG TTC C - 3', and the restriction enzyme was MaellI. PCR was performed using the following reaction conditions: an initial denaturation step of $95^{\circ} \mathrm{C}$ for $5 \mathrm{~min}$, then 30 cycles of annealing with denaturation at $94^{\circ} \mathrm{C}$ for $30 \mathrm{~s}$, touchdown annealing at $60^{\circ} \mathrm{C}$ for $30 \mathrm{~s}$, and final annealing at $72^{\circ} \mathrm{C}$ for $1 \mathrm{~min}$, with a final extension at $72^{\circ} \mathrm{C}$ for $10 \mathrm{~min}$.

\section{Statistical analysis}

Continuous variables were represented as means \pm SD, and categorical variables were expressed as frequencies and percentages. The differences between continuous and categorical variables were evaluated by the two tailed Student's $t$-test and the chi-square test, respectively. The genotype distributions between patients and controls were compared using a chi-square test, and association between genetic polymorphisms and CAD risk was assessed by conditional logistic regression analysis; $\mathrm{OR}$ and $95 \% \mathrm{Cl}$ was taken to evaluate their association. Homozygotes of the most frequent genotype were taken as the reference group. All statistical analyses were performed using SPSS software, version 16.0 (SPSS, Chicago, IL, USA). A P value less than 0.05 was taken as a statistically significant.

\section{RESULTS}

The demographic characteristics and clinical variables of included patients and control subjects are compared in Table 1. In our study, the demographic risk factors that were found to be significantly more prevalent among patients compared with healthy controls included gender, hypertension, type 2 diabetes mellitus, obesity, and tobacco smoking $(P<0.001)$. However, drinking 
status was not significantly different between patients and controls $(P=0.19)$. Furthermore, the mean values of total cholesterol, low- and high density lipoprotein-cholesterol, and triglycerides were significantly different between patients and controls $(P<0.001)$.

Genotype frequencies of IL-1 $\beta+3953 \mathrm{C} / \mathrm{T}$ (rs1143634), IL-6 -174G/C (rs1800795), IL-8 -251T/A (rs4073), and IL-10 -1082A/G (rs1800896) and -819C/T (rs1800871) are shown in Table 2. Genotype frequencies of $I L-6-174 \mathrm{G} / \mathrm{C}$, and $I L-10-1082 A / G$ and $-819 \mathrm{C} / \mathrm{T}$ in the controls were in line with Hardy-Weinberg equilibrium, but the genotypes of $I L-1 \beta+3953 \mathrm{C} / \mathrm{T}$ and $I L-8-251 \mathrm{~T} / \mathrm{A}$ were not. We found that the frequencies of the CC genotype and the $C$ allele of $I L-6-174 \mathrm{G} / \mathrm{C}$ were significantly correlated with a higher risk of CAD; the adjusted ORs (95\%Cls) were 2.37 (1.37-4.14) and 1.49 (1.19-1.86), respectively. The AG and GG genotypes and the $G$ allele of $I L-10-1082 A / G$ were also significantly associated with a higher risk of CAD; the ORs $(95 \% \mathrm{Cls})$ were $1.42(1.04-$ 1.95), 2.16 (1.42-3.30), and 1.56 (1.27-1.93), respectively. However, IL-1 $\beta+3953 \mathrm{C} / \mathrm{T}, I L-8-251 \mathrm{~T} /$ $\mathrm{A}$, and $I L-10-819 \mathrm{C} / \mathrm{T}$ did not significantly correlate with CAD risk.

By interaction analysis, we found that patients carrying the $C$ allele of $I L-6-174 \mathrm{G} / \mathrm{C}$ (rs1800795) and the $G$ allele of $I L-10-1082 A / G$ (rs1800896) were correlated with an elevated risk of $C A D$ in individuals with hypertension, type 2 diabetes mellitus, obesity, and tobacco smoking. However, the $I L-6-174 \mathrm{G} / \mathrm{C}$ and $I L-10-1082 \mathrm{~A} / \mathrm{G}$ gene polymorphisms had no significant interactions with hypertension, type 2 diabetes mellitus, obesity, or tobacco smoking. Furthermore, IL-6 -174G/C (rs1800795) and IL-10 -1082A/G (rs1800896) gene polymorphisms showed no significant association with total cholesterol, low- or high density lipoprotein-cholesterol, or triglycerides in the risk of CAD.

Table 1. Demographic and clinical characteristics of included patients and control subjects.

\begin{tabular}{|c|c|c|c|c|c|c|}
\hline Characteristics & Patients with CAD $(\mathrm{N}=410)$ & $\%$ & Controls $(\mathrm{N}=410)$ & $\%$ & $\mathrm{X}^{2}$ or t-test & $P$ value \\
\hline \multicolumn{7}{|l|}{$\overline{\text { Age }}$} \\
\hline$<60$ & 219 & 53.41 & 222 & 54.15 & & \\
\hline$\geq 60$ & 191 & 46.59 & 188 & 45.85 & 0.04 & 0.83 \\
\hline \multicolumn{7}{|l|}{ Gender } \\
\hline Female & 173 & 42.20 & 233 & 56.83 & & \\
\hline Male & 237 & 57.80 & 177 & 43.17 & 17.56 & $<0.001$ \\
\hline \multicolumn{7}{|l|}{ Hypertension } \\
\hline No & 151 & 36.83 & 71 & 17.32 & & \\
\hline Yes & 259 & 63.17 & 339 & 82.68 & 39.53 & $<0.001$ \\
\hline \multicolumn{7}{|c|}{ Type 2 diabetes mellitus } \\
\hline No & 337 & 82.20 & 379 & 92.44 & & \\
\hline Yes & 73 & 17.80 & 31 & 7.56 & 19.43 & $<0.001$ \\
\hline \multicolumn{7}{|l|}{ Obesity (BMI $\geq 30$ ) } \\
\hline No & 281 & 68.54 & 350 & 85.37 & & \\
\hline Yes & 129 & 31.46 & 60 & 14.63 & 32.74 & $<0.001$ \\
\hline \multicolumn{7}{|l|}{ Tobacco smoking } \\
\hline Never & 92 & 22.44 & 222 & 54.15 & & \\
\hline Current or former & 318 & 77.56 & 188 & 45.85 & 87.22 & $<0.001$ \\
\hline \multicolumn{7}{|l|}{ Alcohol drinking } \\
\hline Never & 155 & 37.80 & 137 & 33.41 & & \\
\hline Current or former & 255 & 62.20 & 273 & 66.59 & 1.72 & 0.19 \\
\hline $\mathrm{TC}(\mathrm{mg} / \mathrm{dL})$ & $196.2 \pm 36.7$ & & $172.4 \pm 32.2$ & & 9.87 & $<0.001$ \\
\hline LDL-c (mg/dL) & $108.1 \pm 28.5$ & & $95.4 \pm 10.2$ & & 8.5 & $<0.001$ \\
\hline HDL-c (mg/dL) & $37.1 \pm 8.2$ & & $42.3 \pm 6.5$ & & 10.06 & $<0.001$ \\
\hline $\mathrm{TG}(\mathrm{mg} / \mathrm{dL})$ & $132.6 \pm 43.2$ & & $117.2 \pm 30.5$ & & 5.9 & $<0.001$ \\
\hline
\end{tabular}

The disease status of hypertension and diabetes mellitus, total cholesterol (TC), low-density lipoprotein cholesterol (LDL-C), high-density lipoprotein cholesterol (HDL-c), and triglycerides (TG) were measured according to standard guidelines and the values were collected from medical records. CAD = coronary artery disease; BMI = body mass index. 


\begin{tabular}{|c|c|c|c|c|c|c|c|c|}
\hline Gene polymorphisms & & $\begin{array}{l}\text { Patients } \\
\text { with CAD }\end{array}$ & $\%$ & Controls & $\%$ & $\begin{array}{l}\text { Hardy-Weinberg } \\
\text { equilibrium }\end{array}$ & OR $(95 \% \mathrm{Cl})^{1}$ & $P$ value \\
\hline \multirow[t]{3}{*}{$I L-1 \beta+3953 \mathrm{C} / \mathrm{T}(\mathrm{rs} 1143634)$} & $\mathrm{CC}$ & 266 & 64.88 & 285 & 69.51 & & 1.0 (Ref.) & - \\
\hline & $\mathrm{CT}$ & 91 & 22.20 & 83 & 20.24 & & $1.17(0.82-1.68)$ & 0.35 \\
\hline & $\mathrm{TT}$ & 54 & 12.93 & 42 & 10.24 & $<0.05$ & $1.38(0.87-2.19)$ & 0.15 \\
\hline \multirow[t]{2}{*}{ Allele } & $\mathrm{C}$ & 623 & 75.98 & 653 & 79.63 & & 1.0 (Ref.) & - \\
\hline & $\mathrm{T}$ & 199 & 24.02 & 167 & 20.37 & & $1.25(0.98-1.59)$ & 0.06 \\
\hline \multirow[t]{3}{*}{ IL-6 -174G/C (rs1800795) } & GG & 198 & 48.29 & 239 & 58.29 & & 1.0 (Ref.) & - \\
\hline & $\mathrm{GC}$ & 163 & 39.76 & 146 & 35.61 & & $1.35(0.99-1.82)$ & 0.05 \\
\hline & $\mathrm{CC}$ & 49 & 11.95 & 25 & 6.10 & 0.67 & $2.37(1.37-4.14)$ & 0.03 \\
\hline \multirow[t]{2}{*}{ Allele } & $\mathrm{G}$ & 559 & 68.17 & 624 & 76.10 & & 1.0 (Ref.) & - \\
\hline & $\mathrm{C}$ & 261 & 31.83 & 196 & 23.90 & & $1.49(1.19-1.86)$ & 0.001 \\
\hline \multirow[t]{3}{*}{ IL-8 -251T/A (rs4073) } & $\mathrm{TT}$ & 118 & 28.78 & 134 & 32.68 & & 1.0 (Ref.) & - \\
\hline & TA & 178 & 43.41 & 171 & 41.71 & & $1.18(0.84-1.66)$ & 0.31 \\
\hline & $\mathrm{AA}$ & 114 & 27.80 & 105 & 25.61 & $<0.05$ & $1.23(0.84-1.80)$ & 0.26 \\
\hline \multirow[t]{2}{*}{ Allele } & $T$ & 414 & 50.49 & 439 & 53.54 & & 1.0 (Ref.) & - \\
\hline & $A$ & 406 & 49.51 & 381 & 46.46 & & $1.13(0.93-1.38)$ & 0.22 \\
\hline \multirow[t]{3}{*}{ IL-10 -1082A/G (rs1800896) } & $\mathrm{AA}$ & 166 & 40.49 & 215 & 52.44 & & 1.0 (Ref.) & - \\
\hline & $A G$ & 158 & 38.54 & 144 & 35.12 & & $1.42(1.04-1.95)$ & 0.02 \\
\hline & GG & 85 & 20.98 & 51 & 12.44 & 0.07 & $2.16(1.42-3.30)$ & 0.04 \\
\hline \multirow[t]{2}{*}{ Allele } & A & 490 & 59.76 & 574 & 70.00 & & 1.0 (Ref.) & - \\
\hline & G & 328 & 40.24 & 246 & 30.00 & & $1.56(1.27-1.93)$ & $<0.001$ \\
\hline \multirow[t]{3}{*}{ IL-10 -819C/T (rs1800871) } & $\mathrm{CC}$ & 153 & 37.32 & 166 & 40.49 & & 1.0 (Ref.) & - \\
\hline & $\mathrm{CT}$ & 177 & 43.17 & 173 & 42.20 & & $1.11(0.81-1.52)$ & 0.5 \\
\hline & $\mathrm{TT}$ & 80 & 19.51 & 71 & 17.32 & 0.28 & $1.22(0.81-1.84)$ & 0.31 \\
\hline \multirow{2}{*}{ Allele } & $\mathrm{C}$ & 483 & 58.90 & 505 & 61.59 & & 1.0 (Ref.) & - \\
\hline & $\mathrm{T}$ & 337 & 41.10 & 315 & 38.41 & & $1.12(0.91-1.37)$ & 0.27 \\
\hline
\end{tabular}

${ }^{1}$ Adjusted for sex, age, hypertension, type 2 diabetes mellitus, obesity, tobacco smoking, total cholesterol, low density lipoprotein cholesterol, high density lipoprotein cholesterol, and triglyceride levels. $C A D=$ coronary artery disease.

\section{DISCUSSION}

Cytokines are involved in modifying immune responses and play a role in maintaining the balance between proinflammatory and anti-inflammatory stimuli in the process of cardiovascular disease. Genetic variants impacting cytokine function might also alter the expression of cytokine genes, and thus influence the pathology of vascular lesions (Weng et al., 2010; Khankhanian et al., 2013). Previous studies have indicated that genetic variants of interleukin genes such as interleukin-1 $\beta(I L-1 \beta), I L-1 \alpha, I L-6, I L-10, I L-16, I L-18$, and IL-23A could affect the development of CAD (Romani et al., 2014; Armingohar et al., 2015; Chi et al., 2015; Jia et al., 2015; Tripathi et al., 2015; Yue et al., 2015), but the results have been inconsistent. In our study, we reported that the IL-6 -174G/C and IL-10 -1082A/G polymorphisms are correlated with an elevated risk of CAD in a multivariate analysis.

The $I L-16$ gene is located at chromosome $15 q 26.3$, and is translated into a 631 amino acid precursor protein (Kim, 1999). The IL-6 gene generates two functional proteins, including a secreted $\mathrm{C}$-terminal peptide with cytokine function and an $\mathrm{N}$-terminal product that functions in cell cycle control. Manginas et al. (2008) conducted a study in small sample size population, and found that the IL-6 -174G/C polymorphism had a critical role in the development of CAD (Manginas et al., 2008). However, Bhanushali and Das (2013) reported no association IL-6 -174G/C variants with CAD risk. In this study, our results supported the findings of the former study, suggesting that the IL-6 -174G/C gene polymorphism was correlated with CAD pathogenesis. Therefore, further large sample studies are greatly needed to confirm our results. 
The human $I L-10$ gene maps to chromosome 1q31-32, and contains three important gene locus mutations upstream of the transcription start site including $/ L-10-1082 \mathrm{G} / \mathrm{A},-819 \mathrm{C} / \mathrm{T}$, and -592C/A (Kim et al., 1992; Turner et al., 1997). Previous studies have demonstrated that the $I L-10$ gene is affected by these upstream polymorphisms (Turner et al., 1997; Eskdale et al., 1998; Koch et al., 2001; Lio et al., 2004); however, the results have been inconsistent. Turner et al. (1997) reported that the three single base pair substitutions in the $I L-10$ gene promoter were correlated with IL-10 protein production in vitro. In another study, Eskdale et al. (1998) suggested that a haplotype of $I L-10$ was associated with the highest overall IL-10 secretion, and that the levels of secreted IL-10 could vary in humans according to the genetic composition of the IL-10 locus. However, more recent reports have demonstrated elevated levels of $I L-10$ associated with promoter polymorphisms (Heiskanen et al., 2010; Assis et al., 2014).

Several previous studies have reported the association between $/ \mathrm{L}-10$ gene polymorphisms and CAD risk, but these results have also been controversial (Yu et al., 2012; Jin et al., 2013; Elsaid et al., 2014; He et al., 2014). Elsaid et al. (2014) conducted a case-control study in an Indian population, and reported that the $C$ allele of $I L-6-174 \mathrm{G} / \mathrm{C}$ ( $\mathrm{rs} 1800795)$ and the $\mathrm{G}$ allele of $I L-10$ $-1082 A / G$ (rs1800896) were associated with an increased risk of CAD. Another study in a Chinese population reported that the $I L-10-592 \mathrm{C} / \mathrm{A}$ polymorphism was also associated with the risk of CAD (Jin et al., 2013). Yu et al. (2012) conducted a study in a Korean population, and reported that the IL-10 -592C/A and -819C/T gene polymorphisms might be associated with ischemic heart disease. However, in one study in a Chinese population, it was reported that $I L-10$ gene polymorphism was not correlated with the risk of CAD (He et al., 2014). In contrast, in a recent meta-analysis of 14 case-control studies with a total of 5006 patients and 3968 controls, it was reported that the IL-10 -1082 gene polymorphism might be associated with an increased overall risk of CAD, especially in Caucasians (Wang et al., 2012). Our results also suggested that the $I L-10-1082 A / G$ (rs1800896) polymorphism was associated with an increased risk of CAD. The discrepancy between these studies might be caused by differences in populations, study design, and sample size.

Limitations of our study include that patients were selected from a single hospital, which might not be representative of the general population. Second, other genetic polymorphisms might influence the development of CAD in addition to the 5 examined in this study. Therefore, further multicenter studies with a larger sample populations including different ethnicities are needed to investigate the role of IL-1 $\beta+3953 \mathrm{C} / \mathrm{T}$ (rs1143634), IL-6 -174G/C (rs1800795), IL-8 -251T/A (rs4073), and IL-10 -1082A/G (rs1800896) and -819C/T (rs1800871) gene polymorphisms on the prognosis of CAD.

In conclusion, our study suggests that the IL-6 -174G/C (rs1800795) and IL-10 -1082A/G (rs1800896) polymorphisms might be involved in the pathogenesis of CAD, and might contribute to the genetic susceptibility for CAD. Further well designed and large sample size studies are greatly needed to confirm our results.

\section{Conflicts of interest}

The authors declare no conflict of interest.

\section{REFERENCES}

Armingohar Z, Jørgensen JJ, Kristoffersen AK, Schenck K, et al. (2015). Polymorphisms in the interleukin-10 gene and chronic periodontitis in patients with atherosclerotic and aortic aneurysmal vascular diseases. J. Oral. Microbiol. 7: 26051.

Assis S, Marques CR, Silva TM, Costa RS, et al. (2014). IL10 single nucleotide polymorphisms are related to upregulation of constitutive IL-10 production and susceptibility to Helicobacter pylori infection. Helicobacter 19: 168-173. 
Bhanushali AA and Das BR (2013). Promoter variants in interleukin-6 and tumor necrosis factor alpha and risk of coronary artery disease in a population from western India. Indian J. Hum. Genet. 19: 430-436.

Chi DZ, Chen J and Huang DP (2015). Influence of interleukin-1 $\beta$ and interleukin- 6 gene polymorphisms on the development of acute pancreatitis. Genet. Mol. Res. 14: 975-980.

Dai CF, Xie X, Ma YT, Yang YN, et al. (2015). Haplotype analyses of CYP17A1 genetic polymorphisms and coronary artery disease in a Uygur population. J. Renin Angiotensin Aldosterone Syst. 16: 389-98.

Elsaid A, Abdel-Aziz AF, Elmougy R and Elwaseef AM (2014). Association of polymorphisms G(-174) C in IL-6 gene and $\mathrm{G}(-1082) \mathrm{A}$ in $\mathrm{LL}-10$ gene with traditional cardiovascular risk factors in patients with coronary artery disease. Indian $\mathrm{J}$. Biochem. Biophys. 51: 282-292.

Eskdale J, Gallagher G, Verweij CL, Keijsers V, et al. (1998). Interleukin 10 secretion in relation to human IL-10 locus haplotypes. Proc. Natl. Acad. Sci. U. S. A. 95: 9465-9470.

Go AS, Mozaffarian D, Roger VL, Benjamin EJ, et al. (2014). Heart disease and stroke statistics - 2014 update: a report from the American Heart Association. Circulation 129: e28-292.

Guo YJ, Chen L, Bai YP, Li L, et al. (2010). The ALDH2 Glu504Lys polymorphism is associated with coronary artery disease in Han Chinese: Relation with endothelial ADMA levels. Atherosclerosis 211: 545-550.

Guven M, Ismailoglu Z, Batar B, Unal S, et al. (2015). The effect of genetic polymorphisms of TLR2 and TLR4 in Turkish patients with coronary artery disease. Gene 558: 99-102.

He J, Gu D, Wu X, Reynolds K, et al. (2005). Major causes of death among men and women in China. N. Engl. J. Med. 353 : 1124-1134

He F, Teng X, Gu H, Liu H, et al. (2014). Interleukin-6 receptor rs7529229 T/C polymorphism is associated with left main coronary artery disease phenotype in a Chinese population. Int. J. Mol. Sci. 15: 5623-5633.

Heiskanen M, Kähönen M, Hurme M, Lehtimäki T, et al. (2010). Polymorphism in the IL10 promoter region and early markers of atherosclerosis: the Cardiovascular Risk in Young Finns Study. Atherosclerosis 208: 190-196.

Jia H, Tao F, Liu C, Guo T, et al. (2015). Both interleukin-23A polymorphism and serum interlukin-23 expression are associated with Graves' disease risk. Cell. Immunol. 294: 39-43.

Jin H, Wang Y and Xu LX (2013). Association of interleukin 10 gene -592C/A polymorphism with coronary artery disease. Zhonghua Yi Xue Yi Chuan Xue Za Zhi. 30: 724-728.

Kaur R, Matharoo K, Sharma R and Bhanwer AJ (2013). C-reactive protein +1059 G>C polymorphism in type 2 diabetes and coronary artery disease patients. Meta Gene 1: 82-92.

Khankhanian P, Baranzini SE, Johnson BA, Madireddy L, et al. (2013). Sequencing of the IL6 gene in a case-control study of cerebral palsy in children. BMC Med. Genet. 14: 126.

Kim JM, Brannan Cl, Copeland NG, Jenkins NA, et al. (1992). Structure of the mouse IL-10 gene and chromosomal localization of the mouse and human genes. J. Immunol. 148: 3618-3623.

Kim HS (1999). Assignment of human interleukin 16 (IL16) to chromosome 15q26.3 by radiation hybrid mapping. Cytogenet. Cell Genet. 84: 93.

Koch W, Kastrati A, Böttiger C, Mehilli J, et al. (2001). Interleukin-10 and tumor necrosis factor gene polymorphisms and risk of coronary artery disease and myocardial infarction. Atherosclerosis 159: 137-144.

Lio D, Candore G, Crivello A, Scola L, et al. (2004). Opposite effects of interleukin 10 common gene polymorphisms in cardiovascular diseases and in successful ageing: Genetic background of male centenarians is protective against coronary heart disease. J. Med. Genet. 41: 790-794.

Manginas A, Tsiavou A, Chaidaroglou A, Giamouzis G, et al. (2008). Inflammatory cytokine gene variants in coronary artery disease patients in Greece. Coron. Artery Dis. 19: 575-582.

Marenberg ME, Risch N, Berkman LF, Floderus B, et al. (1994). Genetic susceptibility to death from coronary heart disease in a study of twins. N. Engl. J. Med. 330: 1041-1046.

Qintao C, Yan L, Changhong D, Xiaoliang G, et al. (2014). Genetic polymorphism of matrix metalloproteinase-1 and coronary artery disease susceptibility: a case-control study in a Han Chinese population. Genet. Test. Mol. Biomarkers 18: 826-831.

Romani S, Hosseini SM, Mohebbi SR, Kazemian S, et al. (2014). Interleukin-16 gene polymorphisms are considerable host genetic factors for patients' susceptibility to chronic hepatitis B infection. Hepat. Res. Treat. 2014: 790753.

Tripathi G, Rangaswamy D, Borkar M, Prasad N, et al. (2015). Interleukin-1 gene cluster variants in hemodialysis patients with end stage renal disease: An association and meta-analysis. Indian J. Nephrol. 25: 34-42.

Turner DM, Williams DM, Sankaran D, Lazarus M, et al. (1997). An investigation of polymorphism in the interleukin-10 gene promoter. Eur. J. Immunogenet. 24: 1-8.

Wan K, Zhao J, Deng Y, Chen X, et al. (2014). A genetic polymorphism in RBP4 is associated with coronary artery disease. Int. J. Mol. Sci. 15: 22309-22319.

Wang Y, Zheng J, Liu P, Yu X, et al. (2012). Association between the interleukin 10-1082G>A polymorphism and coronary heart disease risk in a Caucasian population: a meta-analysis. Int. J. Immunogenet. 39: 144-150. 
Weng KP, Hsieh KS, Hwang YT, Huang SH, et al. (2010). IL-10 polymorphisms are associated with coronary artery lesions in acute stage of Kawasaki disease. Circ. J. 74: 983-989.

Yang XY, Sun JH, Ke HY, Chen YJ, et al. (2014). Metallothionein 2A genetic polymorphism and its correlation to coronary heart disease. Eur. Rev. Med. Pharmacol. Sci. 18: 3747-3753.

Yu GI, Cho HC, Cho YK, Park HS, et al. (2012). Association of promoter region single nucleotide polymorphisms at positions $-819 \mathrm{C} / \mathrm{T}$ and $-592 \mathrm{C} / \mathrm{A}$ of interleukin 10 gene with ischemic heart disease. Inflamm. Res. 61: 899-905.

Yue J, Tong Y, Zhou J, Liu Q, et al. (2015). Genetic variant in interleukin-18 is associated with idiopathic recurrent miscarriage in Chinese Han population. Int. J. Mol. Sci. 16: 4180-4189. 